\title{
Nuclear Power Plant Location Selection in Vietnam under Fuzzy Environment Conditions
}

\author{
Chia-Nan Wang ${ }^{1,2}$, Chih-Chiang Su ${ }^{1,3, *}$ and Van Thanh Nguyen ${ }^{1,4}$ (i) \\ 1 Department of Industrial Engineering and Management, National Kaohsiung University of Science and \\ Technology, Kaohsiung 80778, Taiwan; cn.wang@nkust.edu.tw \\ 2 Department of Industrial Engineering and Management, Fortune Institute of Technology, \\ Kaohsiung 81160, Taiwan \\ 3 Metal Industries and Research Centre, Kaohsiung 83158, Taiwan \\ 4 Department of Industrial Systems Engineering, CanTho University of Technology, Can Tho 900000, Vietnam; \\ jenny9121989@gmail.com \\ * Correspondence: i107143102@nkust.edu.tw
}

Received: 3 October 2018; Accepted: 25 October 2018; Published: 26 October 2018

\begin{abstract}
The demands for energy in general and electrical power in particular in the process of industrialization-modernization in Vietnam are increasing. Although other renewable energy sources such as wind and solar power have been prioritized, they cannot compensate for the shortages of electricity in Vietnam; moreover, traditional energy sources in Vietnam are not endless and will soon reach exhaustion. Nowadays, the government has chosen a solution to maximize domestic energy resources, i.e., develop renewable energy combined with importing coal and gas in appropriate proportions with the construction of nuclear power plants (NPP), which may be the optimal solution to ensure energy security, environmental protection, and sustainable development. However, site selection for construction of a nuclear power plant is one of the most difficult decisions that management faces. Thus, the authors proposed multicriteria decision-making (MCDM), including a fuzzy analytic network process (FANP) and technique for order preference by similarity of an ideal solution (TOPSIS) for NPP location selection in Vietnam. In the first stages of this research, the weight of all criteria and subcriteria will be calculated by an ANP model using fuzzy logic. A TOPSIS model is proposed for ranking all potential locations in the final stage. The results reveal that Binh Thuan is the best place for building an NPP in Vietnam. The contributions of this research include a fuzzy multicriteria decision-making (F-MCDM) approach for NPP site selection in Vietnam. This research also utilizes the evolution of a new approach that is flexible and practical for the decision-maker and provides useful guidelines for NPP site selection in countries around the world.
\end{abstract}

Keywords: nuclear power plant (NPP); site selection; renewable energy; MCDM; FANP; TOPSIS; fuzzy logic

\section{Introduction}

A nuclear power plant is a thermal power station in which the heat source is a nuclear reactor. As is typical of thermal power stations, heat is used to generate steam that drives a steam turbine connected to a generator that produces electricity. Nuclear power is the choice of many countries to ensure energy security and sustainable development as well as actively address environmental issues. By 2015, 30 countries operated NPPs with a total of 391 reactors and a combined installed capacity of 337 GW [1].

Due to the need for a secured future energy supply, Vietnam has decided to include nuclear energy. Site selection is one of the vital steps in designing an NPP. Different places provide different 
analyses of sites and result in different type of nuclear stations that are suitable to build. The selection of a suitable site is the result of a process in which the costs are minimized [2].

In discussing the location selection process, the following main criteria list is important, as it includes region of interest, candidate areas, potential locations, candidate locations, acceptable locations, and preferred locations [2]. Based on the guidelines for site selection for NPP in discussing the site selection process, certain factors need to be discussed, i.e., hydrologic and meteorological characteristics of proposed sites, potential effects on a plant as a result of accidents associated with nearby industries; determination of exclusion area and low population zone; transportation and military facilities; population considerations as they relate to protecting the general public from the potential hazards of serious accidents; emergency planning and security plans, and geologic/seismic [2].

In this work, an MCDM model that includes ANP with fuzzy logic and TOPSIS is proposed for NPP site selection in Vietnam. FANP is applied for defining the weight of all criteria in the first step of this research, and ANP equipped with the triangular fuzzy numbers helps in overcoming the impreciseness and vagueness in the performance. The FANP can be used for ranking NPP site selection, but the weakness of the FANP approaches is that input data, expressed in linguistic terms, notably depends on expert experience. Thus, we proposed a TOPSIS approaches for ranking NPP site selection in the final stages. The steps for implementing the TOPSIS model are as follows:

Step 1: Determine the decision matrix

Step 2: Calculate the weight normalized value $\left(\mathrm{v}_{\mathrm{ij}}\right)$

Step 3: Calculate the PIS $\left(F^{+}\right)$and PIS $\left(F^{-}\right)$

Step 4: Determine a distance of the PIS $\left(Q_{c}^{+}\right)$

Step 5: Determine the relationship proximal to the problem-solving approaches, i.e., proximal relationship from option $F_{C}$ to option $F^{+}$

Step 6: Rank alternatives to determine the best option with the maximum value of $C_{C}$.

The remainder of this article provides background materials to assist in developing the MCDM model. After that, a hybrid FANP and TOPSIS model is developed to select the best site for NPP construction in Vietnam. The results and contributions will be discussed at the end of this article.

\section{Literature Review}

The location selection for NPP is a strategic decision, which has a significant impact on the economic operation of the plant and sustainable development of the region. There are some works that have considered site location for NPP as: Ünal Kurt proposed a fuzzy TOPSIS and generalized Choquet fuzzy integral algorithm for evaluation and selection of optimal locations for NPP in Turkey with many factors [3]. G. Locatelli and M. Mancini have developed and implemented a framework for the selection of the right NPP [4].

Marwan Mossa Lingga [5] involved the development of a decision model for evaluating several potential NPP site technologies, both those that are currently available and future ones. The decision model was developed based on the Hierarchical Decision Modeling (HDM) methodology. Siefi et al. [6] determined the best possible candidates for thermal power plant sites using Multi-criteria Evaluation and Geographic Information System (GIS) in Kahnuj County (southeast of Iran). Kajal Chatterjee et al. [7] proposed a Hybrid MCDM Technique for Risk Management in Construction Projects. Chia Nan Wang et al. [8] proposed a MCDM model for solar panel location selection. David Bailey et al. [9] presented an application of a new fuzzy algorithm for finding and exploring potential solutions to these problems in a raster Geographical Information System (GIS) environment. Ru-xin Nie et al. [10] solvined a solar-wind power station location problem using an extended weighted aggregated sum product assessment (WASPAS) technique with interval neutrosophic sets.

Ridoan Karim [11] studied the opportunities and challenges for nuclear energy development in Bangladesh. Zavadskas et al. [12] proposed a new neutrosophic-The Multi-Objective Optimization 
by Ratio Analysis (MULTIMOORA-MOORA plus the full multiplicative form) method for residential house element and material selection. Peng, Xindong and Liu, Chong [13] presented algorithms for neutrosophic soft decision-making based on EDAS, a new similarity measure and level soft set. This paper presented three novel single-valued neutrosophic soft set (SVNSS) methods. Asad Asadzadeh et al. [14] used TOPSIS model to evaluate site selection of New Towns of Tehran Metropolitan Region (TMR). P. Destiny Ugo [15] proposed a MCDM model for Location Selection in the Niger Delta.

\section{Methodology}

\subsection{Research Development}

In this research, the authors developed a hybrid fuzzy ANP and TOPSIS model for site selection for NPP construction in Vietnam. There are three stages in this work, as shown in Figure 1:

Step 1: Determining the goal and criteria. In this stage, the factors for selecting the optimal sites for NPP will be identified and analyzed. All the subcriteria were built through expert interviews and literature reviews.

Step 2: Implementing the FANP model; there are seven potential sites that can be highly effective for NPP construction that will be considered. In this stage, FANP is applied to determine the weight and subcriteria.

Step 3: The FANP can be used for ranking NPP site selection, but the weakness of the FANP approaches is that input data, expressed in linguistic terms, notably depends on expert experience. Thus, a TOPSIS model is applied in this stage. The ranking list will be defined in this stage.

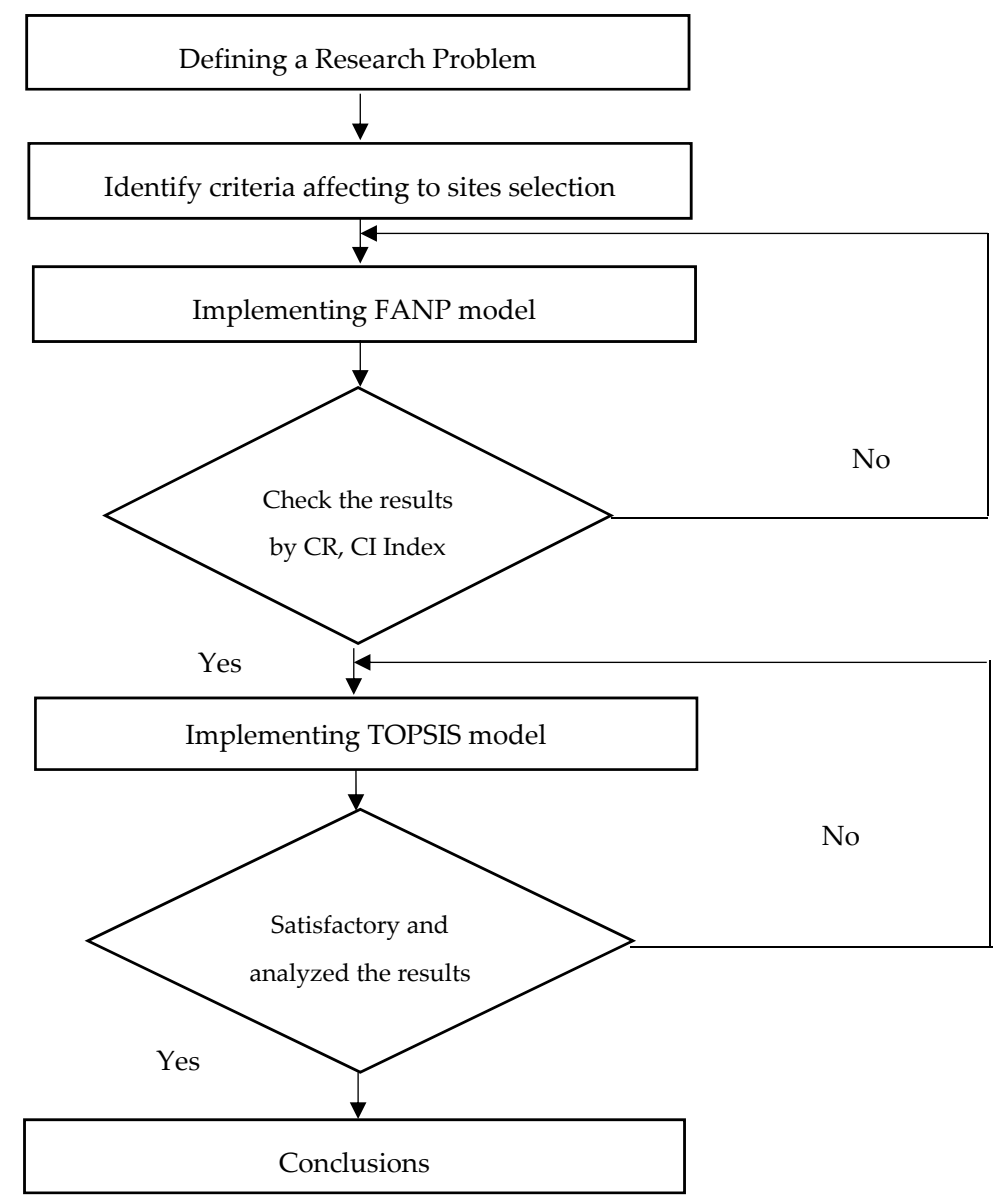

Figure 1. Research methodology. 


\subsection{Methodology}

\subsubsection{Fuzzy Analytic Network Process (FANP)}

ANP does not require a strict hierarchical structure such as AHP. It allows elements to control and be controlled by different levels or clusters of attributes. During the ANP process, the elements will be compared pairwise using the expert rating scale, from which the weighting matrix is established. It is clear that the disadvantage of ANP in dealing with the impression and objectiveness in the pairwise comparison process has been improved in the fuzzy analytic network process. The FANP applies a range of values to incorporate the decision-makers' uncertainty, whereas the FANP model shows a crisp value. However, the ANP stems directly from the AHP, it also inherits theoretical weaknesses of the assumptions of the AHP which, above all, are: The rank reversal problem, the priorities derivation method and the comparison scale [16], and practical decision making with the use of the AHP/ANP can be a nuisance because of a proper reproduction of its assessment scale. Furthermore, experts' evaluations can be inconsistent and imprecise, especially in decision problems which contain many debated alternatives or criteria. Because of decision-makers' imprecise evaluations, the AHP/ANP may not provide a correct solution [17]. This is the reason why TOPSIS model is applied in the final stage for ranking potential locations.

Saaty [18] proposed a FANP model. The triangular fuzzy number (TFN) can be determined as (a, $\mathrm{b}, \mathrm{c})$ with $\mathrm{a} \leq \mathrm{b} \leq \mathrm{c}$. In this research, sites selection were made based on TNF, so this fuzzy number was studied [18-22]. A TFN is shown in Figure 2.

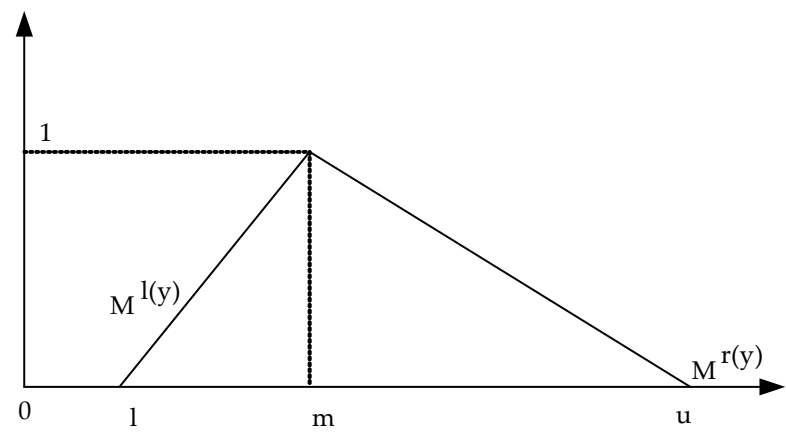

Figure 2. Triangular Fuzzy Number.

TFN can be describe as:

$$
\mu\left(\frac{x}{\widetilde{F}}\right)=\left\{\begin{array}{cc}
0, & x<a \\
\frac{x-a}{b-a} & a \leq x \leq b, \\
\frac{c-x}{c-a} & b \leq x \leq c, \\
0, & x>c
\end{array}\right.
$$

A (F) is given by the representatives of each level of the membership function as following:

$$
\widetilde{M}=\left(M^{l(y)}, M^{r(y)}\right)=[a+(b-a) y, c+(b-c) y], y \in[0,1]
$$

$l(y), r(y)$ indicates both the left and the right side of a NF. Two positive TFN $\left(a_{11}, b_{11}, c_{11}\right)$ and $\left(a_{12}, b_{12}\right.$, $c_{12}$ ) are presented as following:

$$
\begin{gathered}
\left(a_{11}, b_{11}, c_{11}\right)+\left(a_{12}, b_{12}, c_{12}\right)=\left(a_{11}+a_{12}, b_{11}+b_{12}, c_{11}+c_{12}\right) \\
\left(a_{11}, b_{11}, c_{11}\right)-\left(a_{12}, b_{12}, c_{12}\right)=\left(a_{11}-a_{12}, b_{11}-b_{12}, c_{11}-c_{12}\right) \\
\left(a_{11}, b_{11}, c_{11}\right) \times\left(a_{12}, b_{12}, c_{12}\right)=\left(a_{11} \times a_{12}, b_{11} \times b_{12}, c_{11} \times c_{12}\right) \\
\frac{\left(a_{11}, b_{11}, c_{11}\right)}{\left(a_{12}, b_{12}, c_{12}\right)}=\left(a_{11} / c_{12}, b_{11} / b_{12}, c_{11} / c_{12}\right)
\end{gathered}
$$

If $\mathrm{a}=\mathrm{b}=\mathrm{c}$, the FN A becomes a real number $[23,24]$. 
The procedure for implementing the FANP method is as follows:

Step 1: Construction FANP model

Building of the FANP approach structure. Set the hierarchy between the factors as well as the sites.

Step 2: Setting up a pairwise comparison matrix

A pair-comparison of $\mathrm{FN}$ is used to perform a pairwise comparison between factors together. The pair-comparison matrix is defined as follows:

$$
\widetilde{B^{k}}=\left[\begin{array}{cccc}
\widetilde{b_{11}^{k}} & \widetilde{b_{12}^{k}} & \cdots & \widetilde{b_{1 n}^{k}} \\
\widetilde{b_{21}^{k}} & \widetilde{b_{22}^{k}} & \cdots & \vec{b}_{2 n}^{k} \\
\cdots & \cdots & \cdots & \cdots \\
\widetilde{b_{n 1}^{k}} & \widetilde{b_{n 2}^{k}} & \cdots & \widetilde{b_{n n}^{k}}
\end{array}\right]
$$

Converting fuzzy numbers to real numbers, triangular fuzzy trigonometric methods are presented as follows [25]:

$$
\begin{gathered}
t_{\alpha, \beta}\left(\bar{\alpha}_{i j}\right)=\left[\beta f_{\alpha}\left(A_{i j}\right)+(1-\beta) f_{\alpha}\left(C_{i j}\right)\right] ; \\
0 \leq \beta \leq 1,0 \leq \alpha \leq 1
\end{gathered}
$$

where:

$$
\begin{aligned}
f_{\alpha}\left(A_{i j}\right) & =\left(B_{i j}-A_{i j}\right) \alpha+A_{i j} \\
f_{\alpha}\left(C_{i j}\right) & =C_{i j}-\left(C_{i j}-B_{i j}\right) \alpha
\end{aligned}
$$

When matching the diagonal matrix, we have:

$$
\begin{gathered}
t_{\alpha, \beta}\left(\bar{\alpha}_{i j}\right)=\frac{1}{t_{\alpha, \beta}\left(\bar{\alpha}_{i j}\right)} \\
0 \leq \beta \leq 1,0 \leq \alpha \leq 1, \quad i>j
\end{gathered}
$$

Element shows the importance of the indicator $i$ versus the column elements.

$$
C=\left(n_{i j}\right)_{m x m}=\left[\begin{array}{cccc}
1 & n_{12} & \ldots & n_{1 m} \\
n_{21} & 1 & \ldots & n_{2 m} \\
\vdots & \vdots & \vdots & \vdots \\
n_{m 1} & m_{n 2} & \ldots & 1
\end{array}\right]
$$

Evaluating the priority in the FANP approaches that can use the scale are shown in Table 1:

Table 1. Fuzzy conversion scale [26].

\begin{tabular}{cc}
\hline Fuzzy Scale & Linguistic Variables \\
\hline$\widetilde{1}=(1,1,1)$ & Equally important \\
\hline$\widetilde{3}=(2,3,4)$ & Moderately important \\
\hline$\widetilde{5}=(4,5,6)$ & Strongly important \\
\hline$\widetilde{7}=(7,8,9)$ & Very strongly important \\
\hline$\widetilde{9}=(9,9,9)$ & Extremely strongly important \\
\hline & Intermediate values between two adjacent judgments; \\
$\widetilde{2}, \widetilde{4}, \widetilde{6}, \widetilde{8}$ & $\widetilde{4}=(1,2,3) ;$ \\
& $\widetilde{6}=(5,6,7) ;$ \\
& $\widetilde{8}=(7,8,9) ;$ \\
\hline
\end{tabular}


These scales were proposed by Saaty and are shown in Table 2 [27].

Table 2. Priority rating scale.

\begin{tabular}{cc}
\hline Priority Level & Number \\
\hline Equally preferred & 1 \\
Moderately preferred & 3 \\
Strongly preferred & 5 \\
Very strongly preferred & 7 \\
Extremely preferred & 9 \\
Intermediate judgment values & $2,4,6,8$ \\
\hline
\end{tabular}

Step 3: Calculating maximum individual value

Calculating the maximum value for the indicator. In particular, the most widely used is Lambda Max (max) by Saaty Proposition [27]

$$
\left|C-\lambda_{\max } \cdot \mathrm{I}\right|=0
$$

where:

$\lambda_{\max }$ : the maximum value of the matrix.

C: Comparative matrix of pairs of elements.

I: unit matrix of the same level with matrix $C$.

Step 4: Check consistency.

After calculating the maximum individual value, Saaty [27] can use the Consistency Ratio (CR).

$$
\mathrm{CR}=\frac{\mathrm{CI}}{\mathrm{RI}}
$$

If $C R \leq 0.1$ is satisfactory, otherwise if $C R \geq 0.1$ then we must conduct a reevaluation of the pair comparison matrix

$$
\mathrm{CI}=\frac{\lambda_{\max }-\mathrm{n}}{\mathrm{n}-1}
$$

For each n-level comparison matrix, Saaty [27] tested the creation of random matrices and calculated the RI (random index) corresponding to the number of indicators as shown in Table 3 below:

Table 3. Randomized index values corresponding to indicators.

\begin{tabular}{ccccccccccc}
\hline $\mathrm{N}$ & 1 & 2 & 3 & 4 & 5 & 6 & 7 & 8 & 9 & 10 \\
\hline $\mathrm{R}$ & 0 & 0 & 0.52 & 0.90 & 1.12 & 1.24 & 1.32 & 1.41 & 1.45 & 1.49 \\
\hline
\end{tabular}

Step 5: Form the super matrix

After completing the above steps, a super matrix in Table 4 is formed as follows:

Table 4. Super matrix.

\begin{tabular}{ccc}
\hline 0 & $\mathrm{U}_{12}$ & 0 \\
\hline $\mathrm{U}_{21}$ & $\mathrm{U}_{22}$ & $\mathrm{U}_{23}$ \\
\hline 0 & 0 & 0 \\
\hline
\end{tabular}

3.2.2. Technique for Order Preference by Similarity to Ideal Solution (TOPSIS)

The TOPSIS procedure can be expressed in a series of following steps [26,28,29] 
Step 1. Constructing the decision matrix and determining the weight of criteria.

Let $Y=\left(y_{i j}\right)$ be a decision matrix and $V=\left[v_{1}, v_{2}, \ldots, v_{m}\right]$ a weight vector, where $\mathrm{y}_{\mathrm{ij}} \in \Re, \mathrm{v}_{\mathrm{j}} \in \Re$ and $v_{1}+v_{2}+\cdots+v_{m}=1$.

Step 2. Calculating the normalized decision matrix.

Some of the most frequently used methods for calculating the normalized value $n_{i j}$ are the following:

$$
\begin{gathered}
m_{i j}=\frac{y_{i j}}{\sqrt{\sum_{i=1}^{n} y_{i j}^{2}}} \\
m_{i j}=\frac{y_{i j}}{\max y_{i j}} \\
m_{i j}=\left\{\begin{array}{c}
\frac{y_{i j}-\min _{i} y_{i j}}{\max _{i} y_{i j}-\min _{i j} y_{i j}} \text { if } C_{i} \text { is a benifit criterion } \\
\frac{\max _{i} y_{i j}-y_{i j}}{\max _{i} y_{i j}-\min _{i} y_{i j}} \text { if } C_{i} \text { is a cost criterion }
\end{array}\right.
\end{gathered}
$$

for $i=1, \ldots, \mathrm{n} ; j=1, \ldots, \mathrm{m}$.

Step 3. Calculating the weighted normalized decision matrix.

The weighted normalized value $u_{i j}$ is calculated as following:

$$
u_{i j}=v_{j} m_{i j} \quad \text { for } i=1, \ldots, n ; j=1, \ldots, m .
$$

where $v_{j}$ is the weight of the $j$-th criterion, $\sum_{j=1}^{m} v_{j}=1$.

Step 4. Determine the positive ideal solutions (PIS) and negative ideal solutions (NIS).

The PIS is the solution that maximizes the benefit factors and minimizes the cost criteria whereas the NIS maximizes the cost criteria and minimizes the benefit factors.

PIS $B^{+}$has the form:

$$
B^{+}=\left(u_{1}^{+}, u_{2}^{+}, \ldots, u_{n}^{+}\right)=\left(\left(\max _{i} u_{i j} \mid j \in I\right),\left(\min _{i} u_{i j} \mid j \in J\right)\right)
$$

NIS $B^{-}$has the form:

$$
B^{-}=\left(u_{1}^{-}, u_{2}^{-}, \ldots, u_{n}^{-}\right)=\left(\left(\max _{i} u_{i j} \mid j \in I\right),\left(\min _{i} u_{i j} \mid j \in J\right)\right)
$$

Step 5. Calculating the separation measures from the positive ideal solution (PIS) and the negative ideal solution (NIS). The separation of each alternative from the PIS is given as.

$$
e_{i}^{+}=\left(\sum_{j=1}^{n}\left(u_{i j}-u_{n}^{+}\right)^{p}\right)^{1 / p}, i=1,2, \ldots, m
$$

The separation of each alternative from the NIS is given as

$$
e_{i}^{-}=\left(\sum_{j=1}^{n}\left(u_{i j}-u_{n}^{-}\right)^{p}\right)^{1 / p}, i=1,2, \ldots, m
$$

where $p \geq 1$. For $p=2$ we have the most used traditional n-dimensional Euclidean metric. 


$$
\begin{aligned}
& e_{i}^{+}=\sqrt{\sum_{j=1}^{n}\left(u_{i j}-u_{j}^{+}\right)^{2}}, i=1,2, \ldots, m \\
& e_{i}^{-}=\sqrt{\sum_{j=1}^{n}\left(u_{i j}-u_{j}^{-}\right)^{2}}, i=1,2, \ldots, m
\end{aligned}
$$

Step 6. Calculating the relative closeness to the positive ideal solution.

$$
R_{i}=\frac{e_{i}^{-}}{e_{i}^{-}+e_{i}^{+}}
$$

Step 7. Rank the alternatives list or select the alternative closest to 1.

\section{Case Study}

To compensate for the shortage of power due to the current state of the country's energy resources, Vietnam needs to build not only one but many nuclear power plants in the future. According to calculations in the pre-feasibility study, by 2025, Vietnam will have between 2000 and $4000 \mathrm{MW}$ of nuclear power. Nuclear power generation will account for 7-9\% of the country's total electricity output.

In Vietnam, the development of nuclear energy in accordance with the Strategy for Peaceful Utilization of Atomic Energy up to the year 2020 was signed by the prime minister on 3 January 2006. Therefore, the construction of nuclear power plants in Vietnam is reasonable. A nuclear power plant model is shown in Figure 3.

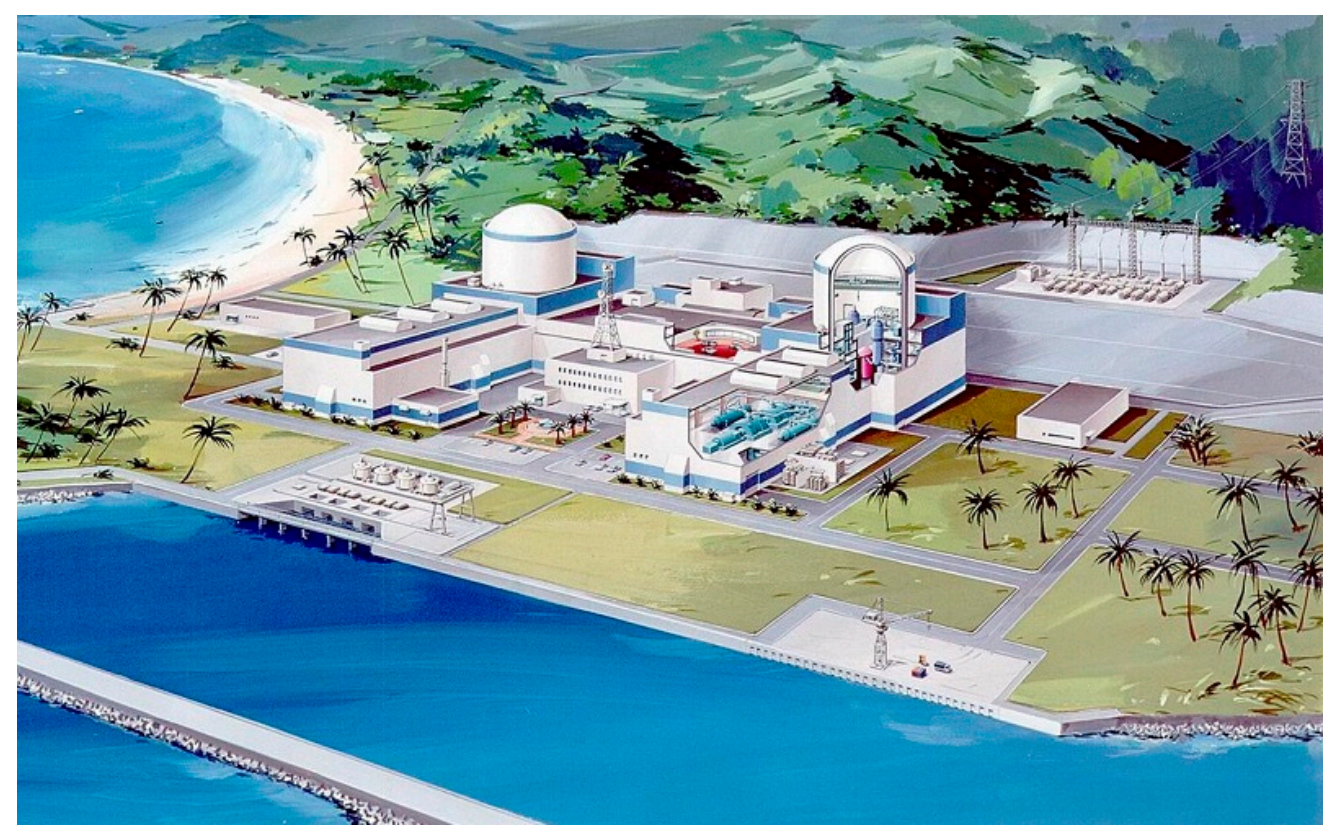

Figure 3. Nuclear Power Plant Model.

In this research, seven potential sites are considered through expert interviews and literature reviews, which are able to invest in NPP, as shown in Table 5.

The main aim of this work is to study in detail the location selection in NPP construction. In this process of site selection for building an NPP in Vietnam, the main factors are discussed based on the regulations for environmental radiation protection of a nuclear power plant [30] and some previous works [31-35]: Reliability and Security of the Site (C1), Site Characteristics Corresponding 
to Environmental Compatibility (C2), Economic Rationality (C3), and Technical Feasibility (C4). The hierarchical structures of the FANP model are shown in Figure 4.

Table 5. Seven potential sites for building NPP in Vietnam.

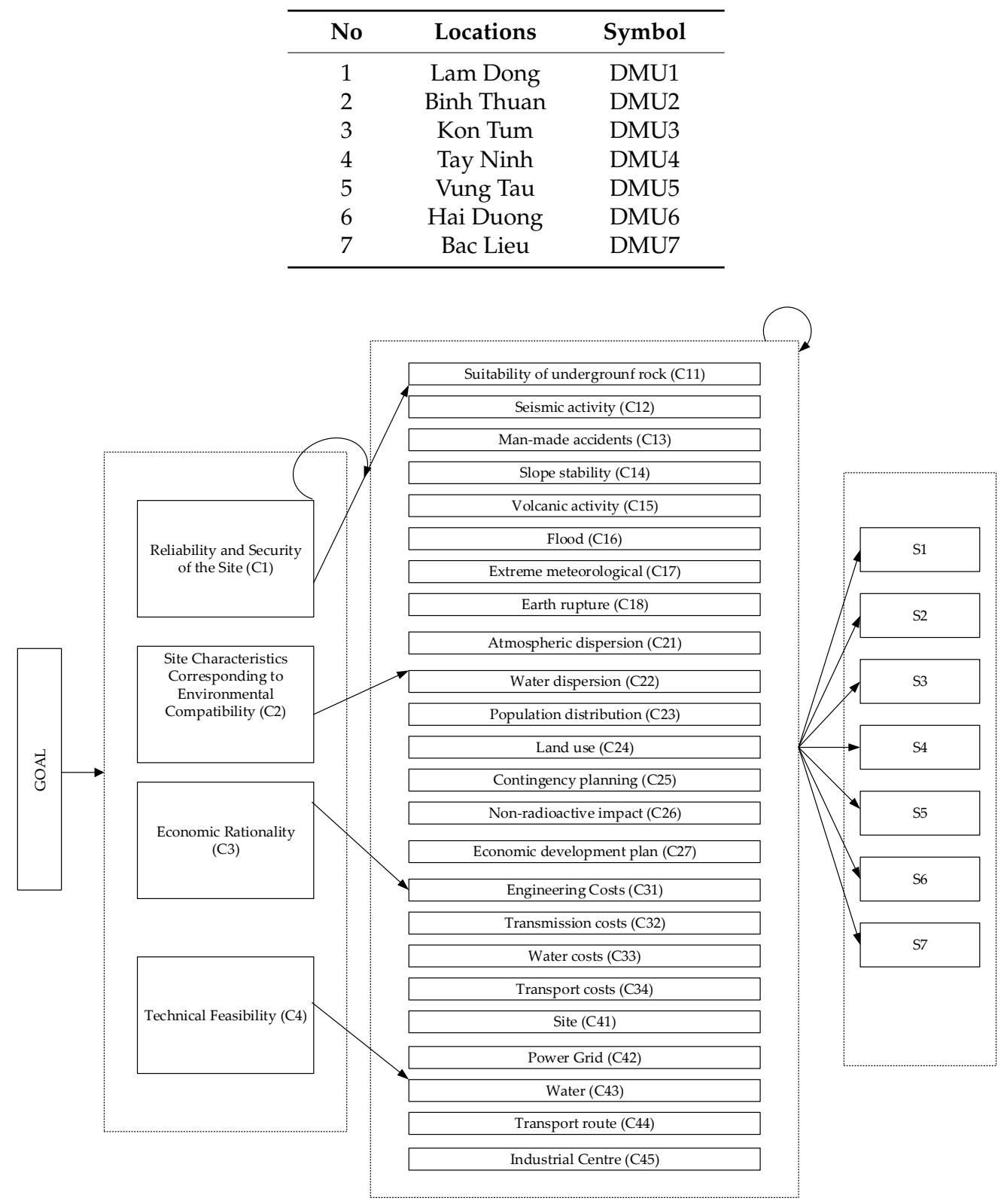

Figure 4. The hierarchical structures of the FANP model.

The FANP is applied in the first phase of this research. The aim of the FANP model is to determine the weight of the criteria by the comparison matrix. A fuzzy comparison matrix of main factors are shown in Tables 6-12:

Table 6. Comparison matrix of Criteria.

\begin{tabular}{ccccc}
\hline Criteria & C3 & C1 & C2 & C4 \\
\hline C3 & $(1,1,1)$ & $(2,3,4)$ & $(3,4,5)$ & $(4,5,6)$ \\
C1 & $(1 / 4,1 / 3,1 / 2)$ & $(1,1,1)$ & $(1 / 4,1 / 3,1 / 2)$ & $(1,2,3)$ \\
C2 & $(1 / 5,1 / 4,1 / 3)$ & $(2,3,4)$ & $(1,1,1)$ & $(3,4,5)$ \\
C4 & $(1 / 6,1 / 5,1 / 4)$ & $(1 / 4,1 / 3,1 / 2)$ & $(1 / 5,1 / 4,1 / 3)$ & $(1,1,1)$ \\
\hline
\end{tabular}


Table 7. Real number of criteria.

\begin{tabular}{ccccc}
\hline Criteria & C3 & C1 & C2 & C4 \\
\hline C3 & 1 & 3 & 4 & 5 \\
C1 & $1 / 3$ & 1 & $1 / 3$ & 2 \\
C2 & $1 / 4$ & 3 & 1 & 4 \\
C4 & $1 / 5$ & $1 / 2$ & $1 / 4$ & 1 \\
\hline
\end{tabular}

Table 8. Comparison matrix of Criteria.

\begin{tabular}{cccccc}
\hline Criteria & C3 & C1 & C2 & C4 & Weight \\
\hline C3 & $(1,1,1)$ & $(2,3,4)$ & $(3,4,5)$ & $(4,5,6)$ & 0.546139 \\
C1 & $(1 / 4,1 / 3,1 / 2)$ & $(1,1,1)$ & $(1 / 4,1 / 3,1 / 2)$ & $(1,2,3)$ & 0.128058 \\
C2 & $(1 / 5,1 / 4,1 / 3)$ & $(2,3,4)$ & $(1,1,1)$ & $(3,4,5)$ & 0.252484 \\
C4 & $(1 / 6,1 / 5,1 / 4)$ & $(1 / 4,1 / 3,1 / 2)$ & $(1 / 5,1 / 4,1 / 3)$ & $(1,1,1)$ & 0.07332 \\
\hline \multicolumn{7}{c}{ Total } \\
\hline
\end{tabular}

Table 9. Comparison matrix of Reliability and Security of the Site (C1).

\begin{tabular}{ccccc}
\hline Criteria & C3 & C2 & C4 & Weight \\
\hline C3 & $(1,1,1)$ & $(2,3,4)$ & $(2,3,4)$ & 0.593634 \\
C2 & $(1 / 4,1 / 3,1 / 2)$ & $(1,1,1)$ & $(1,2,3)$ & 0.249311 \\
C4 & $(1 / 4,1 / 3,1 / 2)$ & $(1 / 3,1 / 2,1)$ & $(1,1,1)$ & 0.157056 \\
\hline \multicolumn{5}{c}{ Total } \\
\hline \multicolumn{5}{c}{ CR $=0.05156$} \\
\hline
\end{tabular}

Table 10. Comparison matrix of Site Characteristics Corresponding to Environmental Compatibility (C2).

\begin{tabular}{ccccc}
\hline Criteria & C3 & C1 & C4 & Weight \\
\hline C3 & $(1,1,1)$ & $(1 / 4,1 / 3,1 / 2)$ & $(1,2,3)$ & 0.24931 \\
C1 & $(2,3,4)$ & $(1,1,1)$ & $(2,3,4)$ & 0.593634 \\
C4 & $(1 / 3,1 / 2,1)$ & $(1 / 4,1 / 3,1 / 2)$ & $(1,1,1)$ & 0.157056 \\
\hline \multicolumn{5}{c}{ Total } \\
\hline \multicolumn{5}{c}{ CR $=0.05156$} \\
\hline
\end{tabular}

Table 11. Comparison matrix of Economic Rationality (C3).

\begin{tabular}{ccccc}
\hline Criteria & $\mathbf{C 1}$ & $\mathbf{C} 2$ & $\mathbf{C} 4$ & Weight \\
\hline $\mathrm{C} 1$ & $(1,1,1)$ & $(1 / 4,1 / 3,1 / 2)$ & $(1,2,3)$ & 0.24931 \\
$\mathrm{C} 2$ & $(2,3,4)$ & $(1,1,1)$ & $(2,3,4)$ & 0.593634 \\
$\mathrm{C} 4$ & $(1 / 3,1 / 2,1)$ & $(1 / 4,1 / 3,1 / 2)$ & $(1,1,1)$ & 0.157056 \\
\hline \multicolumn{5}{c}{ Total } \\
\hline \multicolumn{5}{c}{$\mathrm{CR}=0.05156$} \\
\hline
\end{tabular}

Table 12. Comparison matrix of Technical Feasibility (C4).

\begin{tabular}{ccccc}
\hline Criteria & C3 & C1 & C2 & Weight \\
\hline C3 & $(1,1,1)$ & $(1 / 4,1 / 3,1 / 2)$ & $(1 / 5,1 / 4,1 / 3)$ & 0.117221 \\
C1 & $(2,3,4)$ & $(1,1,1)$ & $(1 / 4,1 / 3,1 / 2)$ & 0.268369 \\
C2 & $(3,4,5)$ & $(2,3,4)$ & $(1,1,1)$ & 0.614411 \\
\hline \multicolumn{5}{c}{ Total } \\
\hline \multicolumn{5}{c}{ CR $=0.07069$} \\
\hline
\end{tabular}


To convert the fuzzy numbers to real numbers we proceed to solve the fuzzy clusters using the triangular fuzzy method.

$$
\begin{gathered}
\mathrm{g} 0.5,0.5\left(\overline{a_{\mathrm{C} 3, \mathrm{C} 2}}\right)=[(0.5 \times 3.5)+(1-0.5) \times 4.5]=4 \\
\mathrm{f}_{0.5}\left(\mathrm{~L}_{\mathrm{C} 3, \mathrm{C} 2}\right)=(4-3) \times 0.5+3=3.5 \\
\mathrm{f}_{0.5}\left(\mathrm{U}_{\mathrm{C} 3, \mathrm{C} 2}\right)=5-(5-4) \times 0.5=4.5 \\
\mathrm{~g} 0.5,0.5\left(\overline{a_{\mathrm{C} 2, \mathrm{C} 3}}\right)=1 / 4
\end{gathered}
$$

The remaining cells similar properties

$$
\begin{aligned}
& \mathrm{GM} 1=(1 \times 4 \times 3 \times 5)^{1 / 4}=2.7832 \\
& \text { GM2 }=(1 / 3 \times 1 / 3 \times 1 \times 2)^{1 / 4}=0.6866 \\
& \text { GM3 }=(1 / 4 \times 1 \times 3 \times 4)^{1 / 4}=1.3161 \\
& \text { GM4 }=(1 / 5 \times 1 / 4 \times 1 / 2 \times 1)^{1 / 4}=0.3977 \\
& \sum G M=\mathrm{GM} 1+\mathrm{GM} 2+\mathrm{GM} 3+\mathrm{GM} 4=5.1836 \\
& \omega_{1}=\frac{2.7832}{5.1836}=0.5369 \\
& \omega_{2}=\frac{0.6866}{5.1836}=0.1325 \\
& \omega_{3}=\frac{1.3161}{5.1836}=0.2539 \\
& \omega_{4}=\frac{0.3977}{5.1836}=0.0767 \\
& {\left[\begin{array}{cccc}
1 & 3 & 4 & 5 \\
1 / 3 & 1 & 1 / 3 & 2 \\
1 / 4 & 3 & 1 & 4 \\
1 / 5 & 1 / 2 & 1 / 4 & 1
\end{array}\right] \times\left[\begin{array}{l}
0.5369 \\
0.1325 \\
0.2539 \\
0.0767
\end{array}\right]=\left[\begin{array}{l}
2.3335 \\
0.5495 \\
1.0924 \\
0.3138
\end{array}\right]} \\
& {\left[\begin{array}{l}
2.3335 \\
0.5495 \\
1.0924 \\
0.3138
\end{array}\right] /\left[\begin{array}{l}
0.5369 \\
0.1325 \\
0.2539 \\
0.0767
\end{array}\right]=\left[\begin{array}{l}
4.3462 \\
4.1472 \\
4.3025 \\
4.0913
\end{array}\right]}
\end{aligned}
$$

With the number of main criteria is 4 , we obtain $n=4, \lambda_{\max }$ and $\mathrm{CI}$ are calculated as follows:

$$
\begin{gathered}
\lambda_{\max }=\frac{4.3462+4.1472+4.3025+4.0913}{4}=4.2218 \\
C I=\frac{\lambda_{\max }-n}{n-1}=\frac{4.2218-4}{4-1}=0.0739
\end{gathered}
$$

To calculate $\mathrm{CR}$, for $\mathrm{n}=4$ we obtain $\mathrm{RI}=0.9$

$$
C R=\frac{C I}{R I}=\frac{0.7393}{0.9}=0.0821
$$

We have a consistent score of $C R=0.0821 \leq 0.1$, so the pairwise comparison of key criteria is appropriate, and there is no need to reevaluate. Criteria results are shown in Table 8.

The comparison matrix and calculation of the subcriteria are done utilizing the main criteria noted above. The weight of all subcriteria are shown in Table 13. 
Table 13. The weight of Sub-Criteria are defined by the FANP model.

\begin{tabular}{ccc}
\hline No & Criteria & Weight \\
\hline 1 & Suitability of underground rock (C11) & 0.10912 \\
2 & Seismic activity (C12) & 0.10942 \\
3 & Man-made accidents (C13) & 0.07441 \\
4 & Slope stability (C14) & 0.03890 \\
5 & Volcanic activity (C15) & 0.05306 \\
6 & Flood (C16) & 0.05362 \\
7 & Extreme meteorological (C17) & 0.01546 \\
8 & Earth rupture (C18) & 0.01823 \\
9 & Site (C41) & 0.06722 \\
10 & Power Grid (C42) & 0.06300 \\
11 & Water (C43) & 0.03975 \\
12 & Transport route (C44) & 0.03947 \\
13 & Industrial Centre (C45) & 0.02423 \\
14 & Atmospheric dispersion (C21) & 0.04361 \\
15 & Water dispersion (C22) & 0.04336 \\
16 & Population distribution (C23) & 0.03144 \\
17 & Land use (C24) & 0.02855 \\
18 & Contingency planning (C25) & 0.02717 \\
19 & Non-radioactive impact (C26) & 0.02510 \\
20 & Economic development plan (C27) & 0.00995 \\
21 & Engineering Costs (C31) & 0.02458 \\
22 & Transmission costs (C32) & 0.02401 \\
23 & Water costs (C33) & 0.01965 \\
24 & Transport costs (C34) & 0.01669 \\
\hline & & \\
& &
\end{tabular}

The weight of all criteria are defined, and the TOPSIS model is applied for ranking all potential sites. In this stage, the evaluation matrix is normalized using linear normalization. The normalized matrix and normalized weight matrix from the TOPIS model are shown in Tables 14 and 15.

Table 14. Normalized matrix.

\begin{tabular}{lccccccc}
\hline & DMU 1 & DMU 2 & DMU 3 & DMU 4 & DMU 5 & DMU 6 & DMU 7 \\
\hline C11 & 0.1176 & 0.1765 & 0.2353 & 0.4118 & 0.4118 & 0.5294 & 0.5294 \\
C12 & 0.2430 & 0.1215 & 0.3037 & 0.4252 & 0.4252 & 0.4860 & 0.4860 \\
C13 & 0.4777 & 0.3715 & 0.3184 & 0.4246 & 0.2654 & 0.4246 & 0.3184 \\
C14 & 0.3721 & 0.3721 & 0.3721 & 0.3721 & 0.4961 & 0.2481 & 0.3721 \\
C15 & 0.3780 & 0.3780 & 0.3780 & 0.3780 & 0.3780 & 0.3780 & 0.3780 \\
C16 & 0.3154 & 0.4205 & 0.3679 & 0.4205 & 0.4205 & 0.3154 & 0.3679 \\
C17 & 0.3810 & 0.3810 & 0.2540 & 0.5080 & 0.2540 & 0.5080 & 0.2540 \\
C18 & 0.4724 & 0.4199 & 0.4199 & 0.4199 & 0.3674 & 0.2624 & 0.2099 \\
C21 & 0.2408 & 0.2408 & 0.2408 & 0.4815 & 0.3612 & 0.4815 & 0.4815 \\
C22 & 0.4041 & 0.3030 & 0.4041 & 0.3536 & 0.4546 & 0.3536 & 0.3536 \\
C23 & 0.4246 & 0.4246 & 0.3184 & 0.3184 & 0.3715 & 0.2654 & 0.4777 \\
C24 & 0.3796 & 0.3796 & 0.4339 & 0.4881 & 0.3254 & 0.3254 & 0.2712 \\
C25 & 0.2364 & 0.3152 & 0.3941 & 0.3941 & 0.4729 & 0.3941 & 0.3941 \\
C26 & 0.4104 & 0.4104 & 0.3078 & 0.3078 & 0.2052 & 0.5130 & 0.4104 \\
C27 & 0.3819 & 0.4364 & 0.3819 & 0.3273 & 0.3819 & 0.4364 & 0.2728 \\
C31 & 0.4056 & 0.2433 & 0.3244 & 0.4056 & 0.4867 & 0.4056 & 0.3244 \\
C32 & 0.4104 & 0.4104 & 0.5130 & 0.3078 & 0.4104 & 0.3078 & 0.2052 \\
C33 & 0.3607 & 0.4508 & 0.3607 & 0.4508 & 0.3607 & 0.2705 & 0.3607 \\
C34 & 0.3676 & 0.2941 & 0.4411 & 0.2206 & 0.3676 & 0.5147 & 0.3676 \\
C41 & 0.4125 & 0.5303 & 0.3536 & 0.2946 & 0.3536 & 0.2946 & 0.3536 \\
C42 & 0.3283 & 0.4377 & 0.3283 & 0.3830 & 0.3283 & 0.4377 & 0.3830 \\
C43 & 0.3397 & 0.5095 & 0.3397 & 0.3963 & 0.2831 & 0.3397 & 0.3963 \\
C44 & 0.4927 & 0.0985 & 0.2956 & 0.4927 & 0.2956 & 0.4927 & 0.2956 \\
C45 & 0.1529 & 0.3059 & 0.3824 & 0.3824 & 0.4588 & 0.5353 & 0.3059 \\
\hline
\end{tabular}


Table 15. Normalized weight matrix.

\begin{tabular}{lccccccc}
\hline & DMU 1 & DMU 2 & DMU 3 & DMU 4 & DMU 5 & DMU 6 & DMU 7 \\
\hline C11 & 0.0128 & 0.0193 & 0.0257 & 0.0449 & 0.0449 & 0.0578 & 0.0578 \\
C12 & 0.0266 & 0.0133 & 0.0332 & 0.0465 & 0.0465 & 0.0532 & 0.0532 \\
C13 & 0.0355 & 0.0276 & 0.0237 & 0.0316 & 0.0197 & 0.0316 & 0.0237 \\
C14 & 0.0145 & 0.0145 & 0.0145 & 0.0145 & 0.0193 & 0.0096 & 0.0145 \\
C15 & 0.0201 & 0.0201 & 0.0201 & 0.0201 & 0.0201 & 0.0201 & 0.0201 \\
C16 & 0.0169 & 0.0225 & 0.0197 & 0.0225 & 0.0225 & 0.0169 & 0.0197 \\
C17 & 0.0059 & 0.0059 & 0.0039 & 0.0079 & 0.0039 & 0.0079 & 0.0039 \\
C18 & 0.0086 & 0.0077 & 0.0077 & 0.0077 & 0.0067 & 0.0048 & 0.0038 \\
C21 & 0.0105 & 0.0105 & 0.0105 & 0.0210 & 0.0158 & 0.0210 & 0.0210 \\
C22 & 0.0175 & 0.0131 & 0.0175 & 0.0153 & 0.0197 & 0.0153 & 0.0153 \\
C23 & 0.0133 & 0.0133 & 0.0100 & 0.0100 & 0.0117 & 0.0083 & 0.0150 \\
C24 & 0.0108 & 0.0108 & 0.0124 & 0.0139 & 0.0093 & 0.0093 & 0.0077 \\
C25 & 0.0064 & 0.0086 & 0.0107 & 0.0107 & 0.0128 & 0.0107 & 0.0107 \\
C26 & 0.0103 & 0.0103 & 0.0077 & 0.0077 & 0.0052 & 0.0129 & 0.0103 \\
C27 & 0.0038 & 0.0043 & 0.0038 & 0.0033 & 0.0038 & 0.0043 & 0.0027 \\
C31 & 0.0100 & 0.0060 & 0.0080 & 0.0100 & 0.0120 & 0.0100 & 0.0080 \\
C32 & 0.0099 & 0.0099 & 0.0123 & 0.0074 & 0.0099 & 0.0074 & 0.0049 \\
C33 & 0.0071 & 0.0089 & 0.0071 & 0.0089 & 0.0071 & 0.0053 & 0.0071 \\
C34 & 0.0061 & 0.0049 & 0.0074 & 0.0037 & 0.0061 & 0.0086 & 0.0061 \\
C41 & 0.0277 & 0.0356 & 0.0238 & 0.0198 & 0.0238 & 0.0198 & 0.0238 \\
C42 & 0.0207 & 0.0276 & 0.0207 & 0.0241 & 0.0207 & 0.0276 & 0.0241 \\
C43 & 0.0135 & 0.0203 & 0.0135 & 0.0158 & 0.0113 & 0.0135 & 0.0158 \\
C44 & 0.0194 & 0.0039 & 0.0117 & 0.0194 & 0.0117 & 0.0194 & 0.0117 \\
C45 & 0.0037 & 0.0074 & 0.0093 & 0.0093 & 0.0111 & 0.0130 & 0.0074 \\
\hline
\end{tabular}

\section{Results and Discussion}

Nuclear power plant location selection is identified as a critical issue that could affect the reliability and security of a site, site characteristics corresponding to environmental compatibility, economic rationality, and technical feasibility factors. Further, location selection is complicated, in that decision-makers must have broad perspectives concerning qualitative and quantitative factors.

In this research, seven potential locations in Vietnam are considered. The FANP is applied to define priorities for each potential location. Then, the TOPSIS model is used for ranking DMU. Then, the distance of the PIS $e_{c}^{+}$and the separation from the NIS $e_{c}^{-}$are shown in Table 16.

Table 16. PIS and NIS value from TOPSIS model.

\begin{tabular}{lcccccc}
\hline DMUs & $\boldsymbol{e}^{+}$ & Rank & $\boldsymbol{e}^{-}$ & Rank & $\mathbf{R}$ & Rank \\
\hline DMU1 & 0.0275 & 6 & 0.0582 & 2 & 0.6792 & 2 \\
DMU2 & 0.0172 & 7 & 0.0638 & 1 & 0.7878 & 1 \\
DMU3 & 0.0349 & 5 & 0.0422 & 3 & 0.5473 & 3 \\
DMU4 & 0.0548 & 4 & 0.0234 & 4 & 0.2990 & 4 \\
DMU5 & 0.0548 & 4 & 0.0232 & 5 & 0.2972 & 5 \\
DMU6 & 0.0678 & 1 & 0.0193 & 7 & 0.2216 & 7 \\
DMU7 & 0.0652 & 2 & 0.0193 & 7 & 0.2285 & 6 \\
\hline
\end{tabular}

An FANP model can be applied for ranking potential locations in many countries, but the number of site selections is practically limited because of the number of pairwise comparisons that need to be made and the disadvantage of the FANP approach is that input data, expressed in linguistic terms, depends on the experience of decision makers and thus involves subjectivity. This is a reason why we proposed a TOPSIS model for ranking alternatives in the final stage. Also, the TOPSIS is presented to reaffirm as a systematic method and improve the disadvantage of the FAHP model, as mentioned above. 
The results are summarized in Table 16, i.e., the final location ranking list is DMU2, DMU1, DMU3, DMU4, DMU5, DMU7, and DMU6. The results show that DMU2 is the best site for nuclear power plant construction in Vietnam [20].

\section{Conclusions}

Site selection for a nuclear power plant is one of the most important decisions management will face. Thus, NPP site decision-making is a highly complex process. The main purpose of nuclear power construction is to conserve traditional energy sources, decrease environmental pollution, and reduce the total cost of whole electricity generation.

Renewable energy plant location selection requires involvement of various decision-makers who must evaluate qualitative and quantitative factors. The fact that reliability and security of the site, site characteristics corresponding to environmental compatibility, economic rationality, and technical feasibility for siting selection are considered in decision-making makes this process more complex. Although some researches have proposed a hybrid FANP and TOPSIS model in site selection, few studies have considered nuclear power plant site selection under a fuzzy environment. Besides, there is no work proposed in these models for NPP location selection in Vietnam. This is among the reasons why we proposed hybrid FANP and TOPSIS approaches for NPP site selection. The result reveals that Binh Thuan is the best place for NPP construction in Vietnam because it has the shortest geometric distance from the positive ideal solution (PIS) and the longest geometric distance from the negative ideal solution (NIS).

The contributions of this research propose a hybrid FANP and TOPSIS approach under fuzzy environments for NPP site selection in Vietnam. This paper also utilizes the evolution of an innovation model that is flexible and is practical for the decision-maker. This work further provides useful guidelines for NPP location selection in many countries.

In future research, it is suggested that applications be increased through the development of new criteria, subcriteria, and models such as fuzzy TOPSIS [36], Data Envelopment Analysis (DEA), ... for other fields within energy issues.

Author Contributions: In this research, conceptualization, C.-N.W. and C.-C.S.; methodology, C.-C.S.; software; validation, C.-C.S. and V.T.N.; formal analysis, V.T.N.; investigation, C.-N.W.; resources, V.T.N.; data curation, C.-C.S.; writing — original draft preparation, C.-C.S. and V.T.N.; writing—-review and editing, C.-N.W.

Funding: This research was partly supported by MOST107-2622-E-992-012-CC3 from the Ministry of Sciences and Technology, and National Kaohsiung University of Science and Technology in Taiwan.

Acknowledgments: The authors appreciate the support from the National Kaohsiung University of Science and Technology, and Ministry of Sciences and Technology in Taiwan.

Conflicts of Interest: The authors declare no conflict of interest.

\section{References}

1. Schneider, M. The Global Outlook of Nuclear Power and the French Case; Austrian Energy Agency \& Federal Ministry of Agriculture, Forestry, Environment and Water Management: Vienna, Austria, 2015.

2. Dengkil, S. Guidelines for Site Selection Criteria of Nuclear Power Plant; Atomic Energy Licencing Board: Selangor, Malaysia, 2011.

3. Kurt, Ü. The fuzzy TOPSIS and generalized Choquet fuzzy integral algorithm for nuclear power plant site selection-A case study from Turkey. J. Nucl. Sci. Technol. 2014, 51, 1241-1255. [CrossRef]

4. Locatelli, G.; Mancini, M. A framework for the selection of the right nuclear power plant. Int. J. Prod. Res. 2011, 50, 4753-4766. [CrossRef]

5. Lingga, M.M. Developing a Hierarchical Decision Model to Evaluate Nuclear Power Plant Alternative Siting Technologies. Ph.D. Thesis, Department of Engineering and Technology Management, Portland State University, Portland, OR, USA, 2016.

6. Siefi, S.; Karimi, H.; Soffianian, A.; Pourmanafi, S. GIS-Based Multi Criteria Evaluation for Thermal Power Plant Site Selection in Kahnuj County, SE Iran. Civ. Eng. Infrastruct. J. 2017, 50, 179-189. 
7. Erol, İ.; Sencer, S.; Özmen, A.; Searcy, C. Fuzzy MCDM framework for locating a nuclear power plant in Turkey. Energy Policy 2014, 67, 186-197. [CrossRef]

8. Wang, C.-N.; Nguyen, V.T.; Thai, H.T.N.; Duong, D.H. Multi-Criteria Decision Making (MCDM) Approaches for Solar Power Plant Location Selection in Viet Nam. Energies 2018, 11, 1504. [CrossRef]

9. Bailey, D.; Goonetilleke, A.; Campbell, D. A new fuzzy multicriteria evaluation method for group site selection in GIS. J. Multi-Criteria Decis. Anal. 2005, 12, 337-347. [CrossRef]

10. Jafari, H.; Karimi, S.; Nahavandchi, M.; Balist, J. Nuclear power plant locating by WLC \& GIS (Case study: Iran, Hormozgan province). Int. J. Basic Appl. Sci. 2015, 4, 132-139.

11. Karim, R.; Karim, M.; Muhammad-Sukki, F.; Abu-Bakar, S.; Bani, N.; Munir, A.; Kabir, A.; Ardila-Rey, J.; Mas'ud, A. Nuclear Energy Development in Bangladesh: A Study of Opportunities and Challenges. Energies 2018, 11, 1672. [CrossRef]

12. Zavadskas, E.K.; Bausys, R.; Juodagalviene, B.; Garnyte-Sapranaviciene, I. Model for residential house element and material selection by neutrosophic MULTIMOORA method. Eng. Appl. Artif. Intell. 2017, 64, 315-324. [CrossRef]

13. Peng, X.; Liu, C. Algorithms for neutrosophic soft decision making based on EDAS, new similarity measure and level soft set. J. Intell. Fuzzy Syst. 2017, 32, 955-968. [CrossRef]

14. Asadzadeh, A.; Sikder, S.K.; Mahmoudi, F.; Kötter, T. Assessing Site Selection of New Towns Using TOPSIS Method under Entropy Logic: A Case study: New Towns of Tehran Metropolitan Region (TMR). Environ. Manag. Sustain. Dev. 2014, 3, 123-137. [CrossRef]

15. Ugo, P.D. A Multi-Criteria Decision Making for Location Selection in the Niger Delta Using Fuzzy TOPSIS Approach. Int. J. Manag. Bus. Res. 2015, 5, 215-224.

16. Ziemba, P.; Wątróbski, J. Selected Issues of Rank Reversal Problem in ANP Method. In Selected Issues in Experimental Economics; Springer Proceedings in Business and Economics; Springer International Publishing: Cham, Switzerland, 2016; pp. 203-225. [CrossRef]

17. Ziemba, P.; Watróbski, J.; Jankowski, J.; Piwowarski, M. Research on the Properties of the AHP in the Environment of Inaccurate Expert Evaluations. In Selected Issues in Experimental Economics; Springer Proceedings in Business and Economics; Springer International Publishing: Cham, Switzerland, 2016; pp. 227-243. [CrossRef]

18. Zadeh, L. Fuzzy sets. Inf. Control 1965, 8, 338-353. [CrossRef]

19. Lee, H.; Kang, H.-Y.; Hsu, C.-F.; Hung, H.-C. A green supplier selection model for high-tech industry. Expert Syst. Appl. 2009, 36, 7917-7927. [CrossRef]

20. Lee, H.; Kang, H.-Y.; Chang, C.-T. Fuzzy multiple goal programming applied to TFT-LCD supplier selection by downstream manufacturers. Expert Syst. Appl. 2009, 36, 6318-6325. [CrossRef]

21. Lee, H.; Kang, H.-Y.; Wang, W.-P. Analysis of priority mix planning for the fabrication of semiconductors under uncertainty. Int. J. Adv. Manuf. Technol. 2006, 28, 351-361. [CrossRef]

22. Cheng, C.-H. Evaluating weapon systems using ranking fuzzy numbers. Fuzzy Sets Syst. 1999, 107, $25-35$. [CrossRef]

23. Dehghani, M.; Esmaeilian, M.; Tavakkoli-Moghaddam, R. Employing Fuzzy ANP for Green Supplier Selection and Order Allocations: A Case Study. Int. J. Econ. Manag. Soc. Sci. 2013, 2, 565-575.

24. KKahraman, C.; Ertay, T.; Büyüközkan, G. A fuzzy optimization model for QFD planning process using analytic network approach. Eur. J. Oper. Res. 2006, 171, 390-411. [CrossRef]

25. Lin, R.; Lin, J.S.-J.; Chang, J.; Tang, D.; Chao, H.; Julian, P.C. Note on group consistency in analytic hierarchy process. Eur. J. Oper. Res. 2008, 190, 672-678. [CrossRef]

26. Kuswandari, R. Assessment of Different Methods for Measuring the Sustainability of Forest Management Retno Kuswandari. Master's Thesis, University of Twente, Enschede, The Netherlands, December 2004.

27. Saaty, T.L. The Analytic Hierarchy Process: Planning, Priority Setting, Resources Allocation; McGraw-Hill: New York, NY, USA, 1980.

28. Assari, A.; Mahesh, T.M.; Assari, E. Role of public participation in sustainability of historical city: Usage of TOPSIS method. Indian J. Sci. Technol. 2012, 5, 2289-2294.

29. Jahanshahloo, G.R.; Lotfi, F.H.; Izadikhah, M. Extension of the TOPSIS Method for Decision-Making Problems with Fuzzy Data. Appl. Math. Comput. 2006, 181, 1544-1551. [CrossRef]

30. National Standard of the People's Republic of China. Regulations for Environmental Radiation Protection of Nuclear Power Plant; China Standards Publishing House: Beijing, China, 2011. 
31. Blond, R.; Taylor, M.; Margulies, T.; Cunningham, M.; Baranowsky, P.; Denning, R.; Cybulskis, P. Development of Severe-Reactor-Accident Source Terms: 1957-1981; Nuclear Regulatory Commission: Washington, DC, USA, 1982.

32. Nuclear Regulatory Commission. Severe Accident Risks: An Assessment for Five U.S. Nuclear Power Plants; Office of Nuclear Regulatory Research: Washington, DC, USA, 1990.

33. ReVelle CS. Multi-objective regional energy location: Cost versus people proximity trade-offs with Cohon JL. In Proceedings of the 25th American Nuclear Society Meeting, Held in Pasco, Washington, DC, USA, 8-12 September 1981.

34. Riddel, M.; Christine Dwyer, W.D.S. Environmental Risk and Uncertainty: Insights from Yucca Mountain. J. Reg. Sci. 2003, 43, 435-458. [CrossRef]

35. Feldman, L.; Hanahan, R.A. Public perceptions of a radioactively contaminated site: Concerns, remediation preferences, and desired involvement. Environ. Health Perspect. 1996, 104, 1344-1352. [CrossRef] [PubMed]

36. Ziemba, P.; Jankowski, J.; Watróbski, J. Online Comparison System with Certain and Uncertain Criteria Based on Multi-criteria Decision Analysis Method. In ICCCI 2017: Computational Collective Intelligence; Lecture Notes in Computer Science; Springer International Publishing: Cham, Switzerland, 2017; Volume 10449, pp. 579-589. [CrossRef]

(C) 2018 by the authors. Licensee MDPI, Basel, Switzerland. This article is an open access article distributed under the terms and conditions of the Creative Commons Attribution (CC BY) license (http:/ / creativecommons.org/licenses/by/4.0/). 